\title{
The Experimental Determination of the Speed of Piston Rods of Two Pneumatic Cylinders with a Synchronizing Element
}

\author{
Marta Żyłka' \\ 1 Faculty of Mechanical Engineering and Aeronautics, Department of Aerospace Engineering, Rzeszów \\ University of Technology, al. Powstańców Warszawy 8, 35-959 Rzeszów, Poland \\ E-mail:mzylka@prz.edu.pl
}

\begin{abstract}
This article presents an experimental studies of an innovative solution for a system of two pneumatic cylinders with a synchronizing element, loaded with a force of different values. The aim of the research was to obtain the speed characteristics of two piston rods of pneumatic cylinders with the use of a synchronizing element. A comparative analysis of received characteristics was conducted and the criterion of the possibility of applying the synchronizing MZ_SYNCH element was adopted. The element for synchronizing the movement of two piston rods of pneumatic cylinders was called MZ_SYNCH for short. On the basis of the research results it was concluded that the system of two pneumatic actuators with the synchronizing element MZ_SYNCH can be used in rehabilitation devices for passive exercise of lower limbs.
\end{abstract}

Keywords: pneumatic drives, double-acting pneumatic cylinders, rehabilitation devices, the speed of movement of piston rods of pneumatic cylinders.

\section{INTRODUCTION}

During the analysis of the available medical equipment and literature $[12,14,15,21]$ a number of solutions to support the rehabilitation process of human lower limbs were noted. The power supply for these devices is usually electric $[18,23,24,25,27]$, less often hydraulic or pneumatic $[13,16,17,26]$. There are no pneumatically powered devices for the support of passive movements of lower limbs. However, the use of fluid drive elements seems to be more useful in the rehabilitation process due to their characteristics similar to those of human muscles [2].

This phenomenon can be applied to rehabilitation processes, especially for the human lower limbs. Such a solution requires synchronization of the movement of two pneumatic cylinders, which is a difficult issue. During the movement of the piston rods of two double-acting pneumatic cylinders with different external load $\left(F_{1}, F_{2}\right)$, the phenomenon of uneven displacement of these piston rods occurs.
Figure 1 shows a diagram of the movement of the piston rods of two pneumatic cylinders with different external loads. The reason why the same displacements of two piston rods of pneumatic cylinders are not achieved is primarily the compressibility of the working medium - compressed air - and differential self-resistance [7, 6, 9, 15]. The compressibility of the working medium causes that the same amount of the medium supplied to individual actuators has a different volume, and the corresponding displacements of the pistons will have different values $[7,20]$.

In the rehabilitation devices of the human lower limbs, a system implementing simultaneous movement of two piston rods of pneumatic actuators can be applied. The simultaneous movement of both lower limbs, healthy and paralyzed, is important because, as shown in works $[3,5]$, the movements of the healthy limb contribute to the increase of muscle strength in the unhealthy. Simultaneous movement of the limbs could be realized by using the MZ_SYNCH element [23] in rehabilitation devices for passive exercise of the lower limbs. 


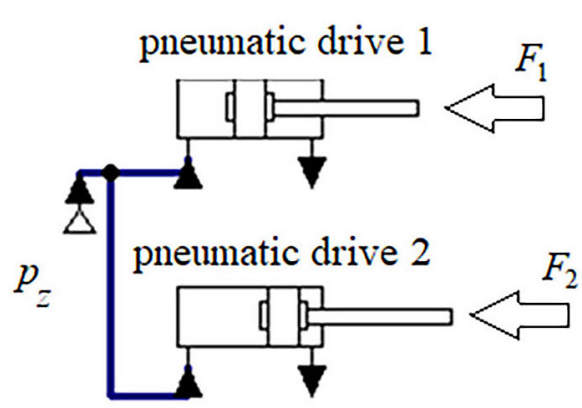

Figure 1. Diagram of the movement of the piston rods of two double-acting pneumatic cylinders with different external loads, where: $F_{1}, F_{2}$ - loading force 1 i 2 pneumatic cylinders $F_{1}>F_{2} ; p_{z}$ - supply pressure; blue line, arrows - compressed air flow

\section{ELEMENT FOR SYNCHRONIZING THE MOVEMENT OF TWO PISTON RODS}

A structural design of an element for synchronizing the movement of two piston rods MZ_SYNCH [23], was formulated and presented in Figure 2.

When one of the actuators (Figure 2) is loaded with a greater force than the other, e.g. actuator SP1, then the pressure in pressure chamber 1a increases, while in the other pressure chamber $1 \mathrm{~b}$ it decreases. Due to the resulting pressure difference between the pressure chambers $1 \mathrm{a}$ and $1 \mathrm{~b}$, the slider 2 changes its position, moving towards the pressure chamber $4 \mathrm{~b}$ with lower air pressure. The pressure equalization, counteracting the blockage of the microslot 3 in the chamber $1 b$, takes place in the equalizing chamber 4 by placing the channels in the side flanges of the slider 5.

\section{RESEARCH METHOD}

In order to check whether the system of two pneumatic actuators with the synchronizing element MZ_SYNCH can be used in rehabilitation equipment, a number of experiments had to be conducted. The purpose of the tests was to obtain speed characteristics of two piston rods of pneumatic actuators. Two pneumatic actuators with the same parameters were used in each cycle.

\section{Extension of piston rods of cylinders at different load values}

The subject of the research were two doubleacting pneumatic cylinders having the same parameters: displacement of the piston rod up to $0.4 \mathrm{~m}$ and piston diameter of $0.04 \mathrm{~m}$. The movement time of the pneumatic actuator piston rod was selected on the basis of the patient's passive lower limb exercises. They should be performed smoothly and gently to avoid pain and harm to the patient and performed at a slow pace $[1,8$, $11,19,21]$. Therefore, a threshold speed of lower limb movement was assumed to be $0.025 \mathrm{~m} / \mathrm{s}$. The pneumatic actuators SP1, SP2 (Figure 3) are designed to support the rehabilitation process by forcing the movement of the lower limbs. The range of pressure values $1.01 \cdot 10^{5}-3.97 \cdot 10^{5} \mathrm{~Pa}$ loading the pneumatic actuators was developed on the basis of the literature $[5,13]$ and accepted.

Based on the literature [18], up to $30 \%$ difference in the loading force of two piston rods was assumed: a healthy limb (e.g. SP1) and a unhealthy limb (e.g. SP2). On this basis, the loading

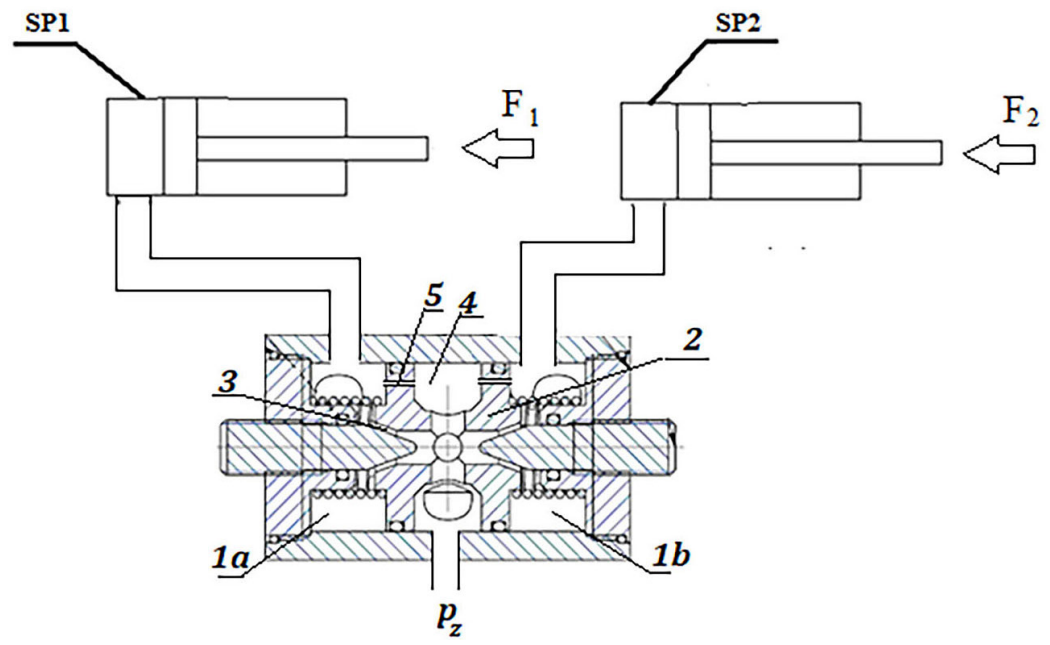

Figure 2. Cross-section of an element for synchronisation of movement of two piston rods:

$1 \mathrm{a}$ - left pressure chamber, $1 \mathrm{~b}$ - right pressure chamber 2 - slider, 3 - microslot,

4 - equalizing chamber, 5 - channels in the side flanges of the slider 
pressures were selected. The measurements were carried out on the test stand shown in Figure 3, with the value of the supply pressure $p_{z}=2,4 \cdot 10^{5} \mathrm{~Pa}$. During the experimental tests, displacements (extension) of piston rods T1, T2 of pneumatic actuators SP1 and SP2 with synchronizing element MZ_SYNCH were measured at various load values $\left(p_{1} \neq p_{2}\right)$, illustrating the situation when one limb is healthy and the other is unhealthy.

The displacement of the piston rods of the two actuators was measured using a potentiometer (6 in Figure 3), every $1 \mathrm{~s}$, using the DASYLab environment, with an accuracy of $0.2 \mathrm{~s}$. The displacement of the two piston rods of the actuators was measured simultaneously. The speed of two piston rods of pneumatic cylinders V1, V2 was determined on the basis of the obtained results. A $15 \%$ difference for the speed of two piston rods of actuators was assumed as the value of correct operation of the system. Two piston rods of the pneumatic cylinders were mechanically connected with piston rods $\mathrm{O} 1, \mathrm{O} 2$ of two actuators SO1, SO2, realizing the load. The load was the pressure, set by pressure reducing valves (4 in Figure 3). The piston rods of the pneumatic cylinders were loaded with different pressures. Three measurements were taken, and in all these measurements the two piston rods of the actuators were loaded with the following pressure:

- piston $\operatorname{rod} \mathrm{T} 1-\mathrm{p}_{1}=1.01 \cdot 10^{5} \mathrm{~Pa}$, piston $\operatorname{rod} \mathrm{T} 2$ $-\mathrm{p}_{2}=1.32 \cdot 10^{5} \mathrm{~Pa}$,

- piston $\operatorname{rod} \mathrm{T} 1-\mathrm{p}_{1}=1.83 \cdot 10^{5} \mathrm{PaPa}$, piston rod $\mathrm{T} 2-\mathrm{p}_{2}=2.38 \cdot 10^{5} \mathrm{~Pa}$,

- piston rod $\mathrm{T} 1-\mathrm{p}_{1}=2.64 \cdot 10^{5} \mathrm{~Pa} \mathrm{~Pa}$, piston rod $\mathrm{T} 2-\mathrm{p}_{2}=3.44 \cdot 10^{5} \mathrm{~Pa}$.

\section{Experimental tests}

Experimental tests were carried out on the measuring stand shown in Figure 3. The experimental tests were conducted at The Faculty of Mechanical Engineering and Aeronautics of Rzeszow University of Technology.

\section{RESULTS}

In the first measurement, piston rod T1 (Figure 4) was loaded with pressure $\mathrm{p}_{1}=1.01 \cdot 10^{5} \mathrm{~Pa}$, while the $\mathrm{T} 2$ piston rod was loaded with $\mathrm{p}_{2}=1.32 \cdot 10^{5} \mathrm{~Pa}$. The displacements (extension) of piston rods T1, T2 of two actuators SP1 and SP2 were measured. On the basis of the obtained results, the speed of extension of these piston rods V1, V2 was determined. The divergence of speed values V1, V2 of the two piston rods of the pneumatic cylinders is shown in Figure 4. The average speed of piston $\operatorname{rod} \mathrm{T} 1$ was $0.017 \mathrm{~m} / \mathrm{s}$, while that of piston $\operatorname{rod} \mathrm{T} 2$ was $0.016 \mathrm{~m} / \mathrm{s}$.

The speed measurement uncertainty is indicated in Figure 4 showing the speed of the two piston rods of the actuators. The time was measured with an accuracy of $0.2 \mathrm{~s}$ and the uncertainty of displacement was taken from the equation (1). The uncertainty of speed of the piston rods was calculated as follows:

$$
\begin{gathered}
V=\frac{s}{t}[\mathrm{~m} / \mathrm{s}] \\
\Delta V=\left|\frac{\Delta s}{t}\right|+\left|-\frac{s \cdot \Delta t}{t^{2}}\right|
\end{gathered}
$$

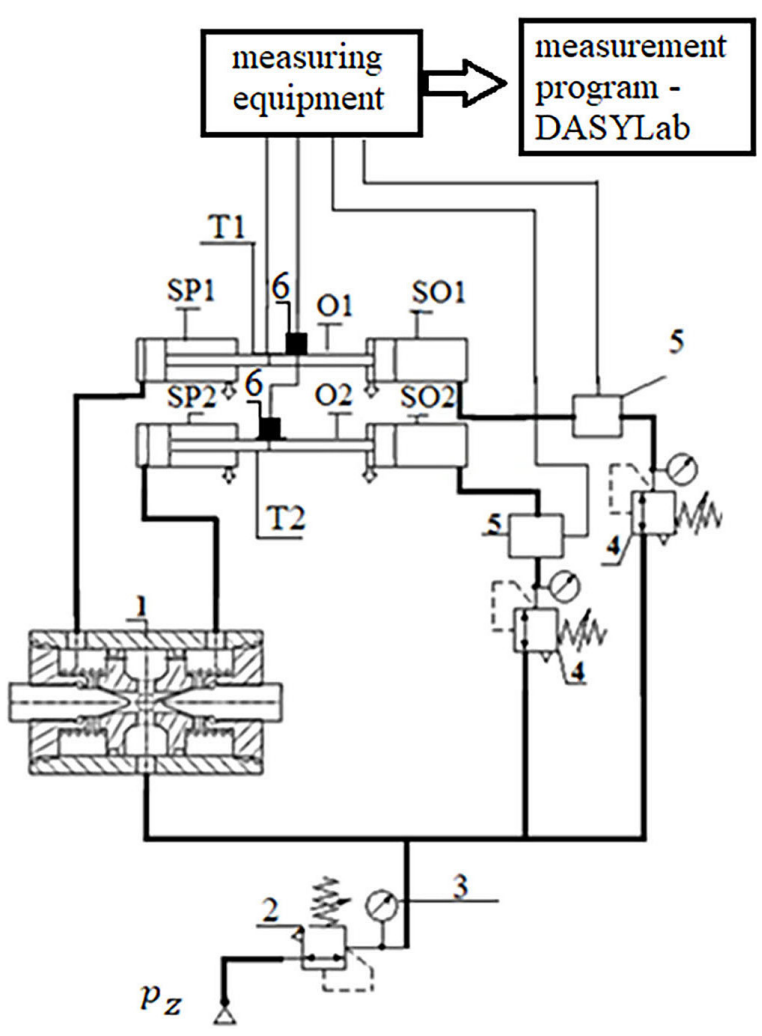

Figure 3. Diagram of the MZ_2 test stand system, where: SP1 - the first tested double-acting pneumatic cylinder, SP2 - the second tested double-acting pneumatic cylinder, T1 - piston rod of the first tested pneumatic cylinder, T2 - piston rod of the second tested pneumatic cylinder, SO1 - the first cylinder loading the limb, SO2 - the second cylinder loading the limb, O1 - the piston rod of the first cylinder loading the limb, $\mathrm{O} 2$ - the piston rod of the second cylinder loading the limb, 1 - synchronizing element MZ_SYNCH, 2 - reduction valve, 3 - manometer, 4 - pressure reducing valves, 5 - pressure sensors, 6 - linear potentiometers, $p_{z}$ - supply pressure 


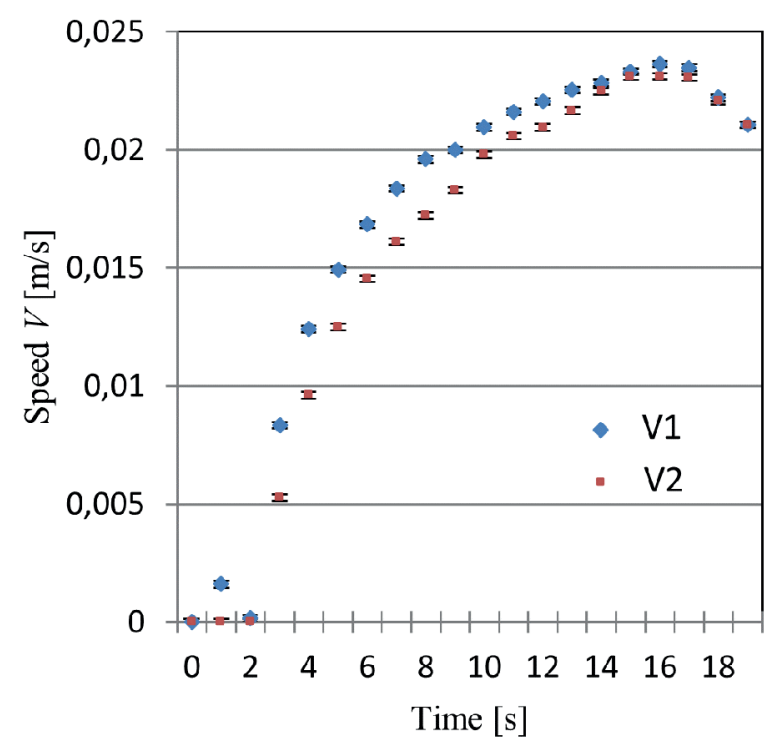

Figure 4. Speed V1, V2 piston

rods $\mathrm{T} 1, \mathrm{~T} 2$. Load $\mathrm{p}_{1}=1.01 \cdot 10^{5} \mathrm{~Pa}, \mathrm{p}_{2}=1.32 \cdot 10^{5} \mathrm{~Pa}$.

where: $\Delta s$ - uncertainty of length measurement; for a linear gauge, 0.5 of the minimum plot is taken,

$\Delta t$ - uncertainty of time measurement.

The method of measuring the speed of two piston rods of pneumatic cylinders enables its determination with an uncertainty of approx. $1.38 \cdot 10^{-4} \mathrm{~m} / \mathrm{s}$. Due to the small value of the uncertainty it was not determined in the other diagrams. Relative speed $\mathrm{R}$ of piston rods $\mathrm{T} 1, \mathrm{~T} 2$ of two pneumatic actuators SP1, SP2 was calculated according to the formula:

$$
R=\frac{V 1_{s} r-V 2_{s} r}{V 1_{s} r} \cdot 100[\%]
$$

where: $R$ - relative speed,

$V 1_{s r}-$ average speed of piston rod $\mathrm{T} 1$ of the actuator $[\mathrm{m} / \mathrm{s}]$,

$V 2_{s r}$ - average speed of piston rod T2 of the actuator $[\mathrm{m} / \mathrm{s}]$.

The relative speed $\mathrm{R}$ of piston rods $\mathrm{T} 1, \mathrm{~T} 2$ of two pneumatic actuators, differently loaded with pressure $\left(\mathrm{p}_{1}=1.01 \cdot 10^{5} \mathrm{~Pa}, \mathrm{p}_{2}=1.32 \cdot 10^{5} \mathrm{~Pa}\right)$, calculated according to the formula (2), has a value of $7.3 \%$.

In the second measurement, piston rod $\mathrm{T} 1$ was loaded with pressure $\mathrm{p}_{1}=1.83 \cdot 10^{5} \mathrm{~Pa}$, and the piston rod T2 with pressure $\mathrm{p}_{2}=2.38 \cdot 10^{5} \mathrm{~Pa}$. The displacements of piston rods T1, T2 of SP1 and SP2 actuators were measured. Based on the results obtained, the speed of the two piston rods of the pneumatic actuators (V1, V2) was determined.

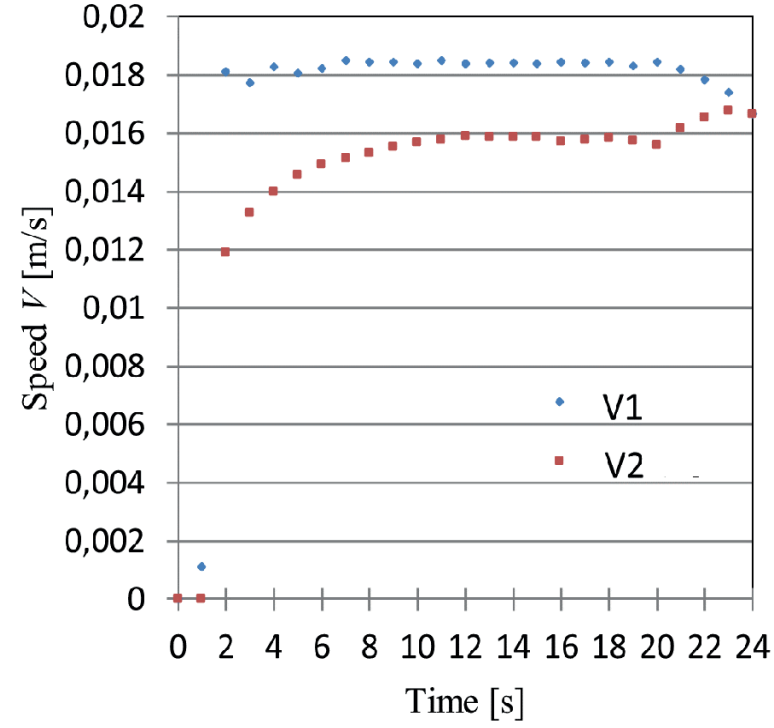

Figure 5. Speed $V 1, V 2$ piston rods $\mathrm{T} 1, \mathrm{~T} 2$. Load $\mathrm{p}_{1}=1.83 \cdot 10^{5} \mathrm{~Pa}, \mathrm{p}_{2}=2.38 \cdot 10^{5} \mathrm{~Pa}$

Figure 5 shows the divergence of speeds V1, V2 of the piston rods. The average speed of piston rod T1 was $0.017 \mathrm{~m} / \mathrm{s}$, while that of piston $\operatorname{rod} \mathrm{T} 2$ was $0.014 \mathrm{~m} / \mathrm{s}$. The relative speed $R$ of piston rods T1, $\mathrm{T} 2$ of the pneumatic cylinders, calculated according to formula (2), at load $\mathrm{p}_{1}=1.83 \cdot 10^{5} \mathrm{~Pa}$ and $\mathrm{p}_{1}=$ $2.38 \cdot 10^{5} \mathrm{~Pa}$, has a value of $15 \%$.

When analysing the results of the measurements in Figure 4 and Figure 5, a decrease in the speed V2 was noticed. At loads $\mathrm{p}_{1}=1.01 \cdot 10^{5} \mathrm{~Pa}$ and $\mathrm{p}_{2}=1.32 \cdot 10^{5} \mathrm{~Pa}$, the average speed of the piston rod V1 was 0.017 $\mathrm{m} / \mathrm{s}$ and $\mathrm{V} 2$ was $0.016 \mathrm{~m} / \mathrm{s}$. In contrast, at load $\mathrm{p}_{1}=1.83 \cdot 10^{5} \mathrm{~Pa}$ and $\mathrm{p}_{2}=2.38 \cdot 10^{5} \mathrm{~Pa}$ the average speed V1 was $0.017 \mathrm{~m} / \mathrm{s}$ and V2 had a value of $0.014 \mathrm{~m} / \mathrm{s}$. No difference was noticed between the V1 speed values, while the V2 speed difference takes the value of $0.002 \mathrm{~m} / \mathrm{s}$. This is a slight difference in speed related to the increase in load on the piston rods of the pneumatic cylinders.

In the third measurement, the piston rod $\mathrm{T} 1$ was loaded with pressure $\mathrm{p}_{1}=2.64 \cdot 10^{5} \mathrm{~Pa}$, while the piston $\operatorname{rod} \mathrm{T} 2$ was loaded with pressure $\mathrm{p}_{2}=3.44 \cdot 10^{5} \mathrm{~Pa}$. The displacement of these piston rods was measured. Based on the results obtained, their speeds V1 and V2 were determined.

The divergence of speed values V1, V2 of piston rods T1, T2 of pneumatic actuators SP1 and SP2 is presented in Figure 6. The average speed of piston $\operatorname{rod} \mathrm{T} 1$ was $0,015 \mathrm{~m} / \mathrm{s}$, and of piston rod $\mathrm{T} 2$ was $0,013 \mathrm{~m} / \mathrm{s}$. Relative speed $\mathrm{R}$ of piston rods $\mathrm{T} 1, \mathrm{~T} 2$ differently loaded $\mathrm{p}_{1}=2.64 \cdot 10^{5} \mathrm{~Pa}$ and $\mathrm{p}_{2}=$ 


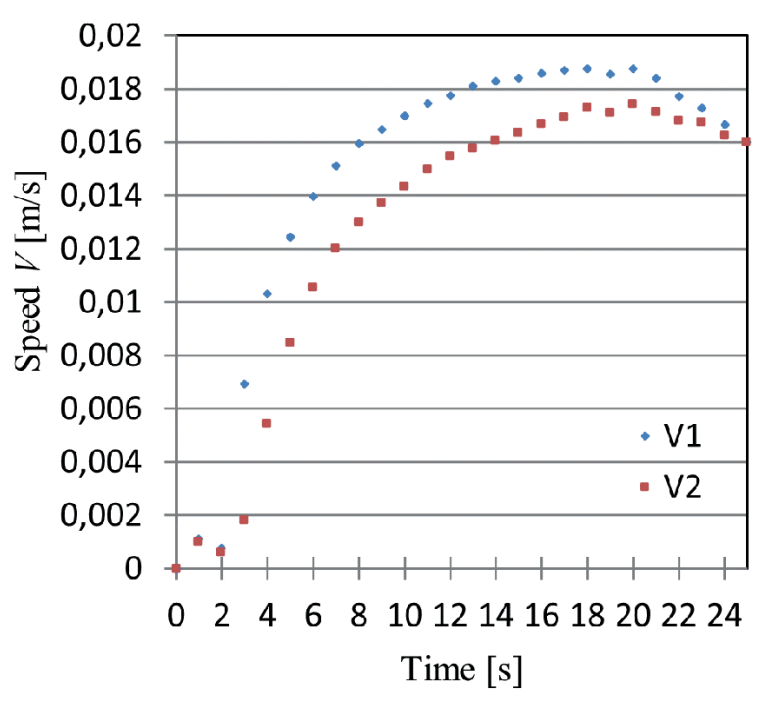

Figure 6. Speed $V 1, V 2$ piston rods $\mathrm{T} 1, \mathrm{~T} 2$. Load $\mathrm{p}_{1}=2.64 \cdot 10^{5} \mathrm{~Pa}, \mathrm{p}_{2}=3.44 \cdot 10^{5} \mathrm{~Pa}$

$3.44 \cdot 10^{5} \mathrm{~Pa}$ calculated according to formula (2), has a value of $13.6 \%$.

On the basis of the results of measurements from Figures 5 and 6 concerning the average speed of extension, a decrease in the average speed of the piston rods of the actuators was noted. At load $\mathrm{Pa}$ and $\mathrm{Pa}$, the average speed of the first piston rod $V 1$ was $0.017 \mathrm{~m} / \mathrm{s}$, and that of the second was $0,014 \mathrm{~m} / \mathrm{s}$. In contrast, at load $\mathrm{Pa}$ and $\mathrm{Pa}$, the average speed of the piston rods was: $V 1=0.015 \mathrm{~m} / \mathrm{s}, V 2=0.013 \mathrm{~m} / \mathrm{s}$. The difference in average speed was: $V 1=0.003 \mathrm{~m} / \mathrm{s}$ and $V 2=$ $0.001 \mathrm{~m} / \mathrm{s}$.

\section{CONCLUSIONS}

Comparing the results of the measurements (Figures 46), concerning the average speed of the piston rods of the actuators, it can be noticed that in the first measurement, with the piston rod T1 loaded with $\mathrm{p}_{1}=1.01 \cdot 10^{5} \mathrm{~Pa}$ and the piston rod $\mathrm{T} 2$ loaded with $\mathrm{p}_{2}=1.32 \cdot 10^{5} \mathrm{~Pa}$, the speed value of $\mathrm{V} 1$ was $0.017 \mathrm{~m} / \mathrm{s}$ and $\mathrm{V} 2$ was $0.016 \mathrm{~m} / \mathrm{s}$. In the second measurement, with a load of $p_{1}=1.83 \cdot 10^{5}$ $\mathrm{Pa}$ on piston rod T1 and a load of $\mathrm{p}_{2}=2.38 \cdot 10^{5} \mathrm{~Pa}$ on piston rod T2, the speed value of $\mathrm{V} 1$ was 0.017 $\mathrm{m} / \mathrm{s}$ and of V2 was $0.014 \mathrm{~m} / \mathrm{s}$. In the third measurement, by loading the piston rod $\mathrm{T} 1$ with a pressure of $\mathrm{p}_{1}=2.64 \cdot 10^{5} \mathrm{~Pa}$ and the piston rod $\mathrm{T} 2$ with a pressure of $\mathrm{p}_{2}=3.44 \cdot 10^{5} \mathrm{~Pa}, \mathrm{~V} 10.015 \mathrm{~m} / \mathrm{s}$ and V2 $0.013 \mathrm{~m} / \mathrm{s}$ were obtained.

Comparing the results obtained, it can be concluded that the lower the load on the piston rods of the actuators, the higher their speed. As the load increases, the speed of the piston rods of the pneumatic actuators decreases, and thus, the higher the load on the patient's limb, the lower the speed of its movement will be.

Some discrepancies between the displacement speeds of the piston rods of the actuators can be observed (Figure 46). The speed V2 of the second piston rod of actuator T2 is lower than the speed V1 of the first piston rod T1 of the actuator. When analyzing the graphs, it was noted that in three measurements, the assumed threshold speed value $(0.025 \mathrm{~m} / \mathrm{s})$ was not exceeded. The differences between the relative speed values of the two piston rods of pneumatic actuators range from $7.3 \%$ to $15 \%$. This difference is mainly related to overcoming the frictional resistance (differentiated own resistance) of the piston rods of the actuators. A great advantage during the rehabilitation of the lower limb is the slow increase of speed during straightening of the patient's limb.

Based on the analysis, a criterion for the applicability of the synchronizing element $\mathrm{MZ}_{-}$ SYNCH was adopted. This element can be used at the following load parameters:

- piston $\operatorname{rod} \mathrm{T} 1-\mathrm{p}_{1}=1.01 \cdot 10^{5} \mathrm{~Pa}$, piston $\operatorname{rod} \mathrm{T} 2$ $-\mathrm{p}_{2}=1.32 \cdot 10^{5} \mathrm{~Pa}$,

- piston $\operatorname{rod} \mathrm{T} 1-\mathrm{p}_{1}=1.83 \cdot 10^{5} \mathrm{~Pa}$, piston $\operatorname{rod} \mathrm{T} 2$ $-\mathrm{p}_{2}=2.38 \cdot 10^{5} \mathrm{~Pa}$,

- piston rod $\mathrm{T} 1-\mathrm{p}_{1}=2.64 \cdot 10^{5} \mathrm{~Pa}$, piston $\operatorname{rod} \mathrm{T} 2$ $-\mathrm{p}_{2}=3.44 \cdot 10^{5} \mathrm{~Pa}$.

According to the presented Figures 4-6, at a supply pressure of $\mathrm{p}_{\mathrm{z}}=2.3 \cdot 10^{5} \mathrm{~Pa}$ and assumed load of piston rods T1, T2 of actuators SP1, SP2, the speed does not exceed the assumed threshold speed of $0.025 \mathrm{~m} / \mathrm{s}$. Therefore, the synchronizing element MZ_SYNCH, taking into account the presented parameters, can be applied in rehabilitation devices for passive exercise of lower limbs.

The results of the research confirmed the correctness and effectiveness of the application of the system of two pneumatic cylinders synchronized with the original element in rehabilitation equipment and indicated possible load ranges related to lower limb movement.

\section{REFERENCES}

1. Biniecki M. Usprawnianie ruchowe w SM. Zestaw ćwiczeń dla osób chorych na stwardnienie rozsiane. Wyd. Polskiego Towarzystwa Stwardnienia Rozsianego Oddział Warszawski; 2011. 
2. Burghardt A.T., Cieślik J., Flaga S. i inni. Wybrane problemy współczesnej robotyki. Wyd. Katedry Automatyzacji Procesów AGH; 2015.

3. Dega W. Ortopedia i rehabilitacja. Tom I. PZWL; 2003.

4. Gedliczka A. Atlas miar człowieka dane do projektowania i oceny ergonomicznej. Centralny Instytut Ochrony Pracy; 2001.

5. Kwolek A. Rehabilitacja w udarze mózgu. Wyd. UR; 2011.

6. Łebkowski P., Węsierski Ł.N., Kost G. Automatyzacja i robotyzacja procesów produkcyjnych. PWE; 2013.

7. Olszewski M. Manipulatory i roboty przemysłowe. WNT; 1992.

8. Prentice W. Rehabilitation Techniques for Sports Medicine and Athletic Training. McGraw-Hill, New York; 2004.

9. Węsierski Ł.N. Pneumatyka. Elementy i układy. Wyd. UR; 2015.

10. Winkler T. Komputerowo wspomagane projektowanie systemów antropotechnicznych. WNT, 2005.

11. Zembaty A. Kinezyterapia. Tom II, Wyd. Kasper; 2003.

12. Agrawal S.K., Banala Sai K., Fattah A., Sangwan V., Krishnamoorthy V., Scholz J.P., Wei-Li H. Assessment of motion of a swing leg and gait rehabilitation with a gravity balancing exoskeleton. IEEE, Trans. on Neural Syst. and Rehabilit. Engin., 2007, 15(3), 410-420.

13. Burdea G., Bouzit M., Popescu V.G., Deutsch J., Stewart A., Girone M. Platform-based System for Ankle Telerehabilitation, invited article, Special Issue on Personal Robotics, Autonomous Robots. 2001(10); 203-212.

14. He T., Sugar J., Design and control of RUPERT: a device for Robotic Upper Extremity Repetitive Therapy. IEEE Transactions on Neural Systems and Rehabilitation Engineering, Teheran. 2007; 15(3):336-346.

15. Koeneman J.B., Koeneman E.J., Sugar T.G., Bha- radwaj K. Design of a Robotic Gait Trainer using Spring Over Muscle Actuators for Ankle Stroke Rehabilitation. Journal of Biomechanical Engineering. 2005;127(6):1009-1013.

16. Kale A., Burdea G., Engsberg J., Janes W., Ross S., Cioi D. Ankle Control and Strengthening for Children with Cerebral Palsy using the Rutgers Ankle CP A case study. W: IEEE International Conference on Rehabilitation Robotics, Zurich 2011, 654-659.

17. Saglia J.A., Tsagarakis N.G., Dai J.S., Caldwell D.G. A high performance 2-dof over-actuated parallel mechanism for ankle. W: Robotics and Automation. IEEE International Conference, Birmingham, 12-17 May 2009, 2180-2185.

18. Schindler-Ivens S., Desimone D., Grubich S., Kelley C., Sanghvi N., Brown D.A. Lower Extremity Passive Range of Motion in Community Ambulating Stroke Survivors, J. Neurol Phys Ther. 2008;32(1):21-31.

19. Zhang X., Yue Z., Wang J. Robotics in Lower-Limb Rehabilitation after Stroke, Behavioural Neurology. 2017(4);1-13.

20.Zhu X., Cao J., Tao G., Yao B., Synchronization strategy research of pneumatic servo system based on separate control of meter-in and mater-out. Advanced Intelligent Mechatronics. IEEE/ASME International Conference, Singapore 2009, 24-29.

21. Żak M. Rehabilitacja w procesie leczenia osób starszych, Gerontologia Polska, 2008, 8(1), 8-12.

22. Byron S., Bio-inspired robotic device could aid ankle-foot rehabilitation USA, IEEE/RSJ. W: International Conference on Intelligent Robots and Systems, USA 2011.

23. Żyłka M., Szczerba Z. Element synchronizujący pracę dwóch siłowników. Utility model number W.126971. From 02.12.2020 r.

24. Catalogue of Biodex Company, 2011.

25. www.meden.com.pl [access: 20.02.2021].

26. www.ronomed.com.pl [access: 10.02.2021].

27. www.technomex.pl [access: 25.02.2021].

28. www.yaskawa.co.jp/en/newsrelease/technology/6637 [access: 15.12.2020]. 